\title{
Simultaneous identification of bovine and equine DNA in milks and dairy products inferred from triplex TaqMan real-time PCR technique
}

\author{
Liang Guo, ${ }^{1}$ Jun-Ping Qian, Yuan-Sheng Guo, Xiao Hai, Guo-Qiang Liu, Jian-Xing Luo, and Mei Ya \\ Xilin Gol Food Testing and Risk Assessment Center, Xilin Gol Institute of Bioengineering, Xilingol Vocational College, Xilinhot 026000, \\ Inner Mongolia, China
}

\begin{abstract}
Koumiss is a popular dairy product in many lands, traditionally prepared from mare milk with spontaneous fermentation. Mare milk and its fermented derivates are more expensive than cow milk and its fermented derivates, and the possibility exists for producers and dealers to adulterate equine products with bovine items. In this work, we described the development of a triplex real-time PCR based on species-specific TaqMan probes for identification of bovine and equine DNA in milks and dairy products. In addition, a novel designed endogenous control was simultaneously amplified to eliminate possible false negatives. With this methodology, bovine and equine DNA were specifically identified by employing developed primers and probes. The limits of detection of this method were $0.001 \mathrm{ng}$ for cow milk, yogurt, and mare milk, and $0.005 \mathrm{ng}$ for sour soup and koumiss, respectively. In addition, the triplex real-time PCR assay for authentication of animal-derived products was effectively validated using binary DNA and milk mixtures, exhibiting well in terms of specificity, sensitivity, and reproducibility. In short, the triplex PCR assay was verified to be a time-saving and moneysaving technique for the identification of bovine and equine DNA in milks and dairy products.
\end{abstract}

Key words: triplex, identification, bovine, equine

\section{INTRODUCTION}

Mare milk is regarded to be close to breast milk in its nutritional composition. In addition, horses and humans assimilate various components of food with the monogastric digestive system, and their milks are therefore similar to each other (Park, 2009). Xilingol herdsmen yield koumiss by the natural fermentation of mare milk. Koumiss has been appealing to Mongolians in Xilin

Received January 7, 2018.

Accepted April 22, 2018.

${ }^{1}$ Corresponding author: herdman86@163.com
Gol of Inner Mongolia, where it has been applied as a traditional Mongolian medicine to cure intestinal dyspepsia, hypertension, dyslipidemia, and so on (Rong et al., 2015; Yao et al., 2017). The above nutritional and medical properties have contributed to the prosperity of the market for mare milk and its dairy products, and consequently have attracted interest for herdsmen and producers in various regions and countries. Nevertheless, the lower milk yield of mare and seasonal milk production determine a higher price compared with cow milk. As a result of a shortage of original material and dispersal natural fermentation in the nomad's yurt, koumiss is more expensive than fermented products derived from cow milk. The big difference in price makes it attractive for herdsmen and producers to adulterate mare with cow milk, and koumiss with sour soup, which is the nickname of acidic whey (the byproduct in the production of Mongolian traditional cheese) in Xilingol.

Various analytical methodologies have been developed to identify the animal species from which meat and milk have been obtained (Anguita et al., 1997; Cozzolino et al., 2002; Ferreira and Cacote, 2003; López-Calleja et al., 2007a; Ballin, 2010; Nakyinsige et al., 2012; Rahmati et al., 2016). Many of these analytical methods for milks and dairy products are based on immunology (Anguita et al., 1997), mass spectrometry (Cozzolino et al., 2002), and chromatographic assay (Ferreira and Cacote, 2003). These protein-based techniques are very specific, but are lowly sensitive, especially for the identification of animal-derived products from thermally processed products. Recently, some DNA-based methods exhibited specific and sensitive features for the discrimination of animal species for heat-treated materials (Ballin, 2010; Rahmati et al., 2016). The PCR-based methods were developed to detect poultry meat adulteration (Soares et al., 2010), beef adulteration (Mane et al., 2012), and bovine milk adulteration with goat cheese (Golinelli et al., 2014). Real-time PCR-based methods using SYBR Green were applied to identify the DNA of cow, goat, sheep, and buffalo for dairy adulteration (Agrimonti et al., 2015). In particular, real-time PCR results can be automati- 
Table 1. TaqMan real-time PCR primers and probes (synthesized by Ruibio Biotec Company, Beijing, China)

\begin{tabular}{ll}
\hline Primer and probe & Sequence $^{1}\left(5^{\prime}\right.$ to $\left.3^{\prime}\right)$ \\
\hline LP1 & TTGAAT(C/T)AGGCCATGAAGC \\
Bovine-LP1 & TTGAATTAGGCCATGAAGC \\
Equine-LP1 & TTGAATCAGGCCATGAAGC \\
RP1 & CTTACCTTGTACGACTTGTCTC \\
Bovine-probe & FAM-CTCTCATGTAGCTAGTGCGTTTAAATAGGG-TAMRA \\
Equine-probe & HEX-TTCATATGTTTGGGTCACGGTTTTATGT-TAMRA \\
Control-probe & ROX-ACACACCGCCCGTCACCCT-BHQ-2 \\
\hline
\end{tabular}

${ }^{1} \mathrm{FAM}=$ fluorescent reporters 6 -carboxyfluorescein; HEX = hexachlorofluorescein; ROX = carboxy-X-rhodamine; TAMRA $=$ tetramethylrhodamine; BHQ-2 = black hole quencher 2.

cally achieved without electrophoresis and exhibit the ability of quantitative analysis.

This work aimed at proposing a novel triplex realtime PCR methodology that was introduced to identify bovine and equine DNA in milks and dairy products with an endogenous control amplification, which was simultaneously used to eliminate possible false negatives. The system was based on the design of relative speciesconservative primers and species-specific probes targeting $12 \mathrm{~S}$ ribosomal gene of mitochondrion DNA, which was more specific and sensitive than conventional PCR, and regarded as a less expensive and more throughput assay compared with simplex real-time PCR.

\section{MATERIALS AND METHODS}

\section{Preparation of Milks and Dairy Products}

Fresh meat samples of beef, horse, mutton, pork, chicken, duck, goose, dog, rabbit, cat, and carp were purchased from 109 supermarkets and DKL shopping mall in Xilinhot. Cow and mare milk were obtained from Plain Mountain Pasture in Xilin Gol of Inner

Table 2. The cycle threshold $(\mathrm{Ct})$ values in the real-time PCR assay for bovine and equine detection in the meats of 11 species

\begin{tabular}{lccc}
\hline & \multicolumn{3}{c}{ Ct value $^{1}$} \\
\cline { 2 - 4 } Sample & Cow-FAM & Mare-HEX & Control-ROX \\
\hline Beef & $16.18 \pm 0.14$ & 0 & $15.88 \pm 0.09$ \\
Horse & 0 & $16.35 \pm 0.32$ & $15.97 \pm 0.17$ \\
Mutton & 0 & 0 & $15.5 \pm 0.17$ \\
Pork & 0 & 0 & $15 \pm 0.04$ \\
Chicken & 0 & 0 & N/A \\
Duck & 0 & 0 & N/A \\
Goose & 0 & 0 & N/A \\
Dog & 0 & 0 & N/A \\
Rabbit & 0 & 0 & N/A \\
Cat & 0 & 0 & N/A \\
Carp & 0 & 0 &
\end{tabular}

${ }^{1}$ Data (average $\pm \mathrm{SD}$ ) represent 3 replicates. FAM $=$ fluorescent reporters 6-carboxyfluorescein; HEX = hexachlorofluorescein; ROX = carboxy-X-rhodamine.

${ }^{2} \mathrm{~N} / \mathrm{A}=$ not applicable.
Mongolia, and 5 samples per species were milked from different individuals. The yogurt, koumiss, and sour soup were collected from Mongolian yurts across the Xilingol grassland, and 5 samples per type originated from different individual families.

\section{Genomic DNA Extraction of Milks and Dairy Products}

The DNA from milks and dairy products were isolated by the modified cetyltrimethyl ammonium bromide method. First, $50 \mathrm{~mL}$ of milks and dairy products were defatted with centrifugation at $13,000 \times g$ for 10 min at
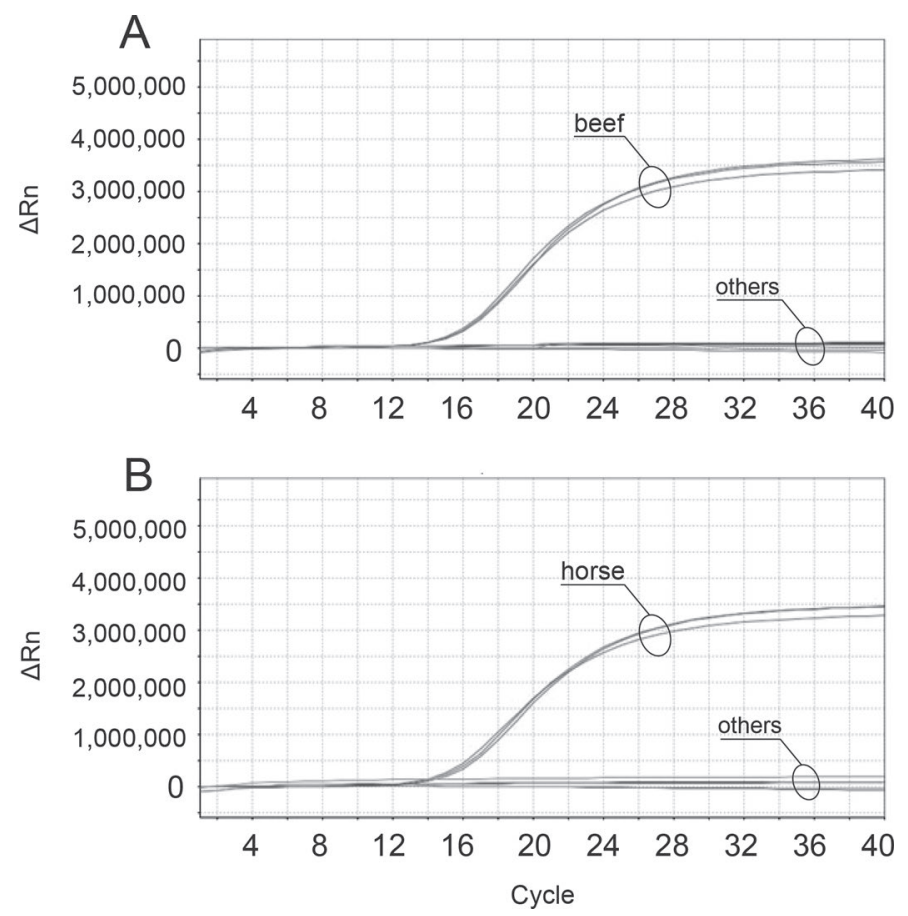

Figure 1. Specificity of bovine and equine primers and probe in the 11 meats. (A) Eleven meats (beef, horse, mutton, pork, chicken, duck, goose, dog, rabbit, cat, and carp) were amplified with bovine-specific primers and probe. (B) Eleven meats were amplified with equine-specific primers and probes. The results were confirmed by 3 replicates. $\Delta \mathrm{Rn}=$ change in normalized reported value 
$4^{\circ} \mathrm{C}$, and the supernatant was discarded by wiping the upper cream with a cotton swab. Then, the precipitate was added to $500 \mu \mathrm{L}$ of PBS followed by completely mixing and centrifuging at $13,000 \times g$ for $10 \mathrm{~min}$ at $4^{\circ} \mathrm{C}$, and discarding the supernatant. The precipitate was added to $540 \mu \mathrm{L}$ of PBS and $60 \mu \mathrm{L}$ of emulsifier followed by completely mixing and centrifuging at $13,000 \times g$ for $10 \mathrm{~min}$ at $4^{\circ} \mathrm{C}$, and the supernatant was discarded. Last, the segment was added to $500 \mu \mathrm{L}$ of PBS and bathed at $40^{\circ} \mathrm{C}$ for $10 \mathrm{~min}$, and the cell pellet was harvested by centrifugation at $13,000 \times g$ for 10 min at room temperature. Further, the DNA from the above cell pellet was extracted according to the standard cetyltrimethyl ammonium bromide method (Murray and Thompson, 1980). The DNA concentration was estimated by NanoDrop 2000 (Thermo Fisher Scientific, Waltham, MA) at a wavelength of $260 \mathrm{~nm}$.

\section{Development of Primers and Probes for Triplex Real-Time PCR}

After alignment of mitochondrial DNA from beef, horse, sheep, pig, chicken, duck, goose, dog, rabbit, cat, and carp, the primers and probes were developed by targeting the species-specific and species-conservative sequences in the $12 \mathrm{~S}$ ribosomal gene of mitochondrion
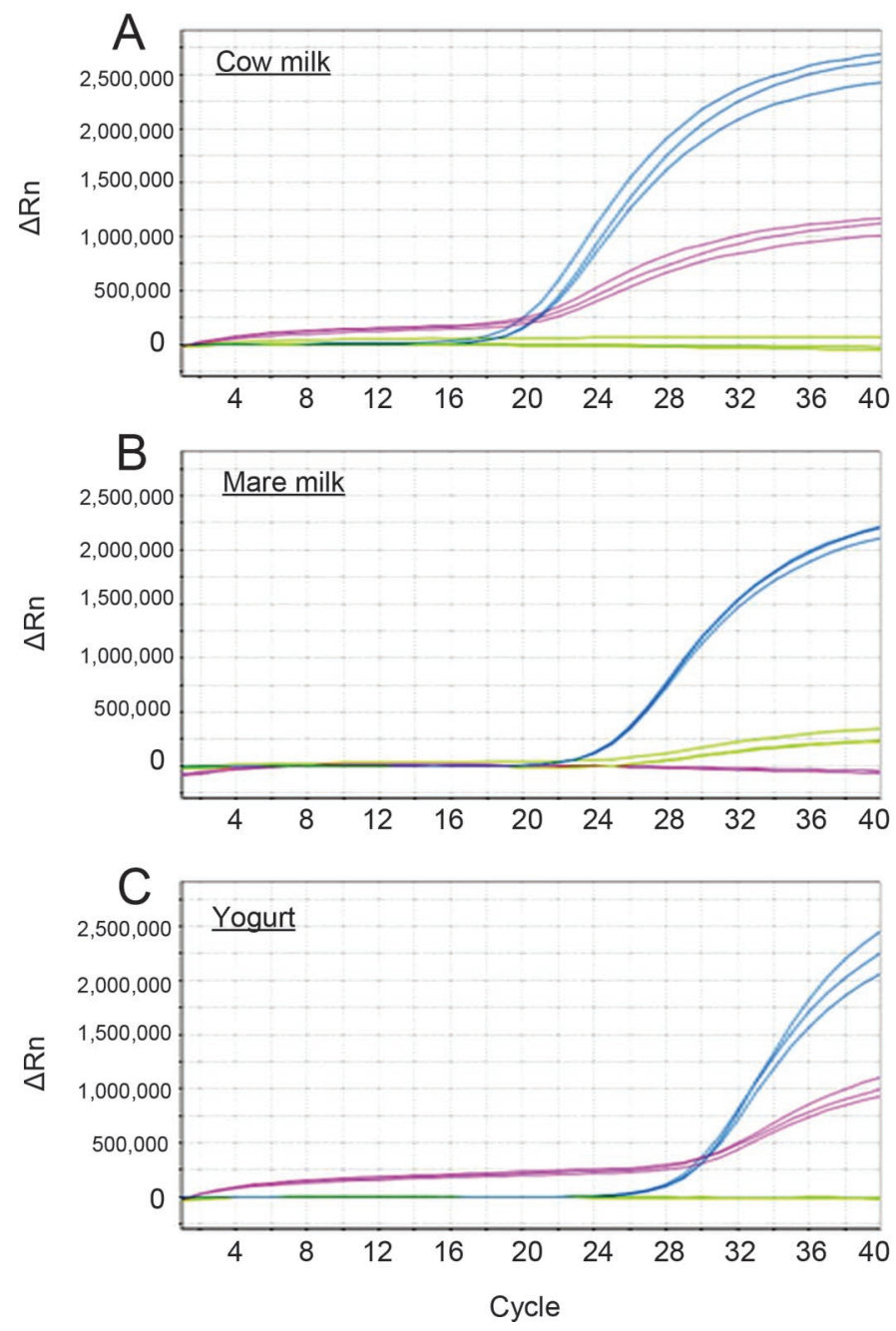
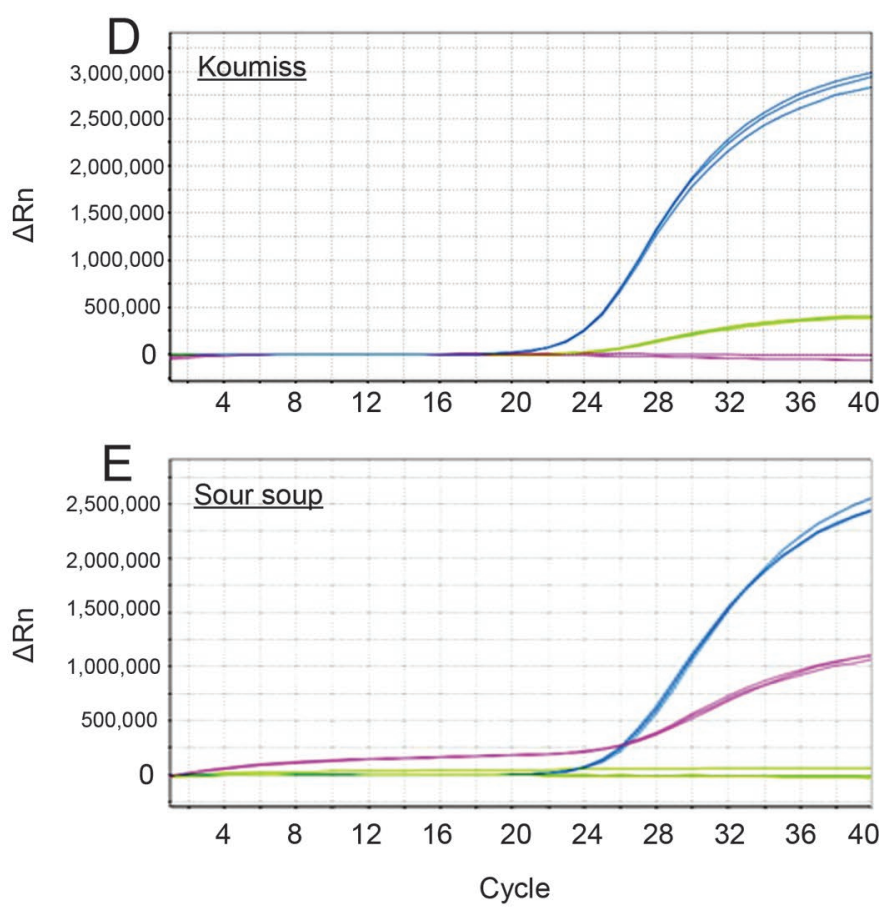

Figure 2. Triplex real-time PCR amplification plots for milks and dairy products. Bovine- and equine-specific probes labeled with fluorescent reporters 6-carboxyfluorescein (FAM; pink curve) and hexachlorofluorescein (HEX; yellow curve) were applied to detect the origin of cow milk (A), mare milk (B), yogurt (C), koumiss (D), and sour soup (E). Probe-carboxy-X-rhodamine (ROX; blue) was used as an endogenous control. The amplification results were confirmed by 3 replicates. $\Delta \mathrm{Rn}=$ change in normalized reported value. 
DNA for probes and primers (Table 1). The probes were purified by HPLC and labeled with the fluorescent reporters 6-carboxyfluorescein (FAM), hexachlorofluorescein $(\mathbf{H E X})$, and carboxy-X-rhodamine (ROX) on the $5^{\prime}$ end and with tetramethylrhodamine and black hole quencher 2 on the $3^{\prime}$ end. The challenge of development was to guarantee simultaneous triplex real-time PCR with conservative and effective endogenous control in one reaction. The designed primers and probes were synthesized and purified using HPLC by Ruibiotech Company (Beijing, China).

\section{Real-Time PCR System and Sensitivity Assay}

Triplex real-time PCR reaction mixtures $(20 \mu \mathrm{L})$ were $10 \mu \mathrm{L}$ of Probe qPCR SuperMix, $1 \mu \mathrm{L}$ of LP1 (10 $\mu \mathrm{mol} / \mathrm{L}), 1 \mu \mathrm{L}$ of RP1 $(10 \mu \mathrm{mol} / \mathrm{L}), 1 \mu \mathrm{L}$ of bovineprobe $(10 \mu \mathrm{mol} / \mathrm{L}), 1 \mu \mathrm{L}$ of equine-probe $(10 \mu \mathrm{mol} / \mathrm{L})$, $1 \mu \mathrm{L}$ of control-probe $(10 \mu \mathrm{mol} / \mathrm{L}), 1 \mu \mathrm{L}$ of template (100 ng/ $\mu \mathrm{L}$ ), $4 \mu \mathrm{L}$ of double-distilled $\mathrm{H}_{2} \mathrm{O}$ (Transgen, Beijing, China). Simplex real-time PCR reaction mixtures for specificity assay in meats were $10 \mu \mathrm{L}$ of Probe qPCR SuperMix, $1 \mu \mathrm{L}$ of bovine-LP1 $(10 \mu \mathrm{mol} / \mathrm{L})$ or equine-LP1 $(10 \mu \mathrm{mol} / \mathrm{L}), 1 \mu \mathrm{L}$ of $\mathrm{RP} 1(10 \mu \mathrm{mol} / \mathrm{L})$, $1 \mu \mathrm{L}$ of bovine-probe $(10 \mu \mathrm{mol} / \mathrm{L})$ or $1 \mu \mathrm{L}$ of equineprobe $(10 \mu \mathrm{mol} / \mathrm{L}), 1 \mu \mathrm{L}$ of template, and $6 \mu \mathrm{L}$ of double-distilled $\mathrm{H}_{2} \mathrm{O}$ (Transgen). The real-time PCR reaction was performed under the following program: $30 \mathrm{~s}$ at $94^{\circ} \mathrm{C}, 40$ cycles of $5 \mathrm{~s}$ at $94^{\circ} \mathrm{C}$, and $31 \mathrm{~s}$ at $60^{\circ} \mathrm{C}$ (ABI 7300plus, Applied Biosystems, Waltham, MA).

The sensitivity assay of the triplex real-time PCR assay was evaluated by the limit of detection (LOD). The LOD were determined using of 10- and 2-fold DNA serial dilutions. Twenty replicates (in 3 different runs) for each dilution were used for the triplex real-time PCR, and results were analyzed as inferred from Probit analysis (Finney, 1971).

\section{RESULTS AND DISCUSSION}

\section{Specificity in the Triplex Real-Time PCR Amplification for Milks and Dairy Products}

Raw meat samples of beef, horse, mutton, pork, chicken, duck, goose, dog, rabbit, cat, and carp were introduced to confirm that the designed primers and probes were bovine- and equine-specific. Bovine-specific probe was labeled with FAM, equine-specific probe was labeled with HEX, and endogenous control probe was labeled with ROX. As shown in Figure 1, the amplification plots specifically appeared in beef (Figure 1A) and horse meat (Figure 1B) using bovine and equine primers and probes, respectively. The cycle threshold $(\mathbf{C t})$ values (average $\pm \mathrm{SD}$ ) in the real-time $\mathrm{PCR}$ assay for the meats of 11 species are shown in Table 2. The $\mathrm{Ct}$ values of beef and horse were $16.18 \pm 0.14$ and 16.35 \pm 0.32 ; other species meats were not amplified with the designed bovine and equine primers and probes. The above results illustrated that the designed primers and probes were specific for cattle and horses, respectively.

The triplex real-time PCR with endogenous control for bovine and equine DNA detection in milks and dairy products were developed using the bovine- and equine-specific primers and probes with 3 fluorescent indicators (FAM, HEX, and ROX). As shown in Figure 2 , the corresponding amplification plots (pink curve: bovine-specific; yellow curve: equine-specific; blue curve: endogenous control) specifically and steadily appeared in cow milk (Figure 2A), mare milk (Figure 2B), yogurt (Figure 2C), koumiss (Figure 2D), and sour soup (Figure $2 \mathrm{E}$ ). The amplification results were confirmed by 3 replicates. The $\mathrm{Ct}$ values of cow milk ( 5 independent samples per assay, 3 replicates per sample), mare milk (5 independent samples, 3 replicates), yogurt (5 independent samples, 3 replicates), koumiss ( 5 independent samples, 3 replicates), and sour soup (5 independent samples, 3 replicates) inferred from triplex real-time PCR are shown in Table 3. Whereas no amplification value was obtained with DNA of the nontarget animal

Table 3. The cycle threshold $(\mathrm{Ct})$ values in the triplex real-time PCR assay for milks and dairy products

\begin{tabular}{|c|c|c|c|}
\hline \multirow[b]{2}{*}{ Sample } & \multicolumn{3}{|c|}{ Ct value ${ }^{1}$} \\
\hline & Cow-FAM & Mare-HEX & Control-ROX \\
\hline Cow milk 1 & $20.68 \pm 0.84$ & 0 & $18.67 \pm 0.57$ \\
\hline Cow milk 2 & $22.16 \pm 2.48$ & 0 & $20.5 \pm 0.66$ \\
\hline Cow milk 3 & $19.42 \pm 0.25$ & 0 & $19.39 \pm 0.12$ \\
\hline Cow milk 4 & $18.21 \pm 0.46$ & 0 & $16.75 \pm 0.16$ \\
\hline Cow milk 5 & $22.57 \pm 0.4$ & 0 & $20.69 \pm 0.88$ \\
\hline Mare milk 1 & 0 & $27.92 \pm 1.89$ & $23.34 \pm 0.06$ \\
\hline Mare milk 2 & 0 & $33.11 \pm 0.61$ & $30.23 \pm 0.25$ \\
\hline Mare milk 3 & 0 & $27.29 \pm 2.87$ & $23.29 \pm 0.51$ \\
\hline Mare milk 4 & 0 & $29.12 \pm 1.59$ & $25.25 \pm 0.75$ \\
\hline Mare milk 5 & 0 & $34.29 \pm 0.81$ & $30.2 \pm 0.35$ \\
\hline Yogurt 1 & $24.76 \pm 3.05$ & 0 & $27.6 \pm 0.19$ \\
\hline Yogurt 2 & $26.04 \pm 0.33$ & 0 & $24.32 \pm 0.55$ \\
\hline Yogurt 3 & $28.45 \pm 1.69$ & 0 & $24.87 \pm 0.32$ \\
\hline Yogurt 4 & $23.96 \pm 0.14$ & 0 & $28.35 \pm 0.89$ \\
\hline Yogurt 5 & $24.03 \pm 0.82$ & 0 & $26.8 \pm 0.58$ \\
\hline Koumiss 1 & 0 & $21.57 \pm 0.24$ & $23.10 \pm 0.04$ \\
\hline Koumiss 2 & 0 & $21.04 \pm 0.32$ & $23.61 \pm 0.28$ \\
\hline Koumiss 3 & 0 & $27.66 \pm 0.34$ & $29.22 \pm 0.16$ \\
\hline Koumiss 4 & 0 & $19.98 \pm 0.88$ & $21.06 \pm 0.12$ \\
\hline Koumiss 5 & 0 & $23.45 \pm 0.35$ & $24.92 \pm 0.02$ \\
\hline Sour soup 1 & $25.27 \pm 0.15$ & 0 & $24.18 \pm 0.16$ \\
\hline Sour soup 2 & $28.69 \pm 3.53$ & 0 & $25.88 \pm 0.72$ \\
\hline Sour soup 3 & $24.09 \pm 1.06$ & 0 & $22.9 \pm 0.65$ \\
\hline Sour soup 4 & $25.92 \pm 0.56$ & 0 & $25.03 \pm 0.04$ \\
\hline Sour soup 5 & $24.75 \pm 1.13$ & 0 & $23.48 \pm 0.32$ \\
\hline
\end{tabular}

${ }^{1}$ Data (average $\pm \mathrm{SD}$ ) represent 3 replicates. FAM $=$ fluorescent reporters 6 -carboxyfluorescein; HEX = hexachlorofluorescein; ROX = carboxy-X-rhodamine. 
species, the $\mathrm{Ct}$ values of the corresponding samples identified by cow-FAM and mare-HEX were steadily shown. The simultaneous control-ROX was applied to confirm the presence of DNA and validate the PCR reaction to get rid of false-negative results. The above data illustrated that the triplex real-time PCR with
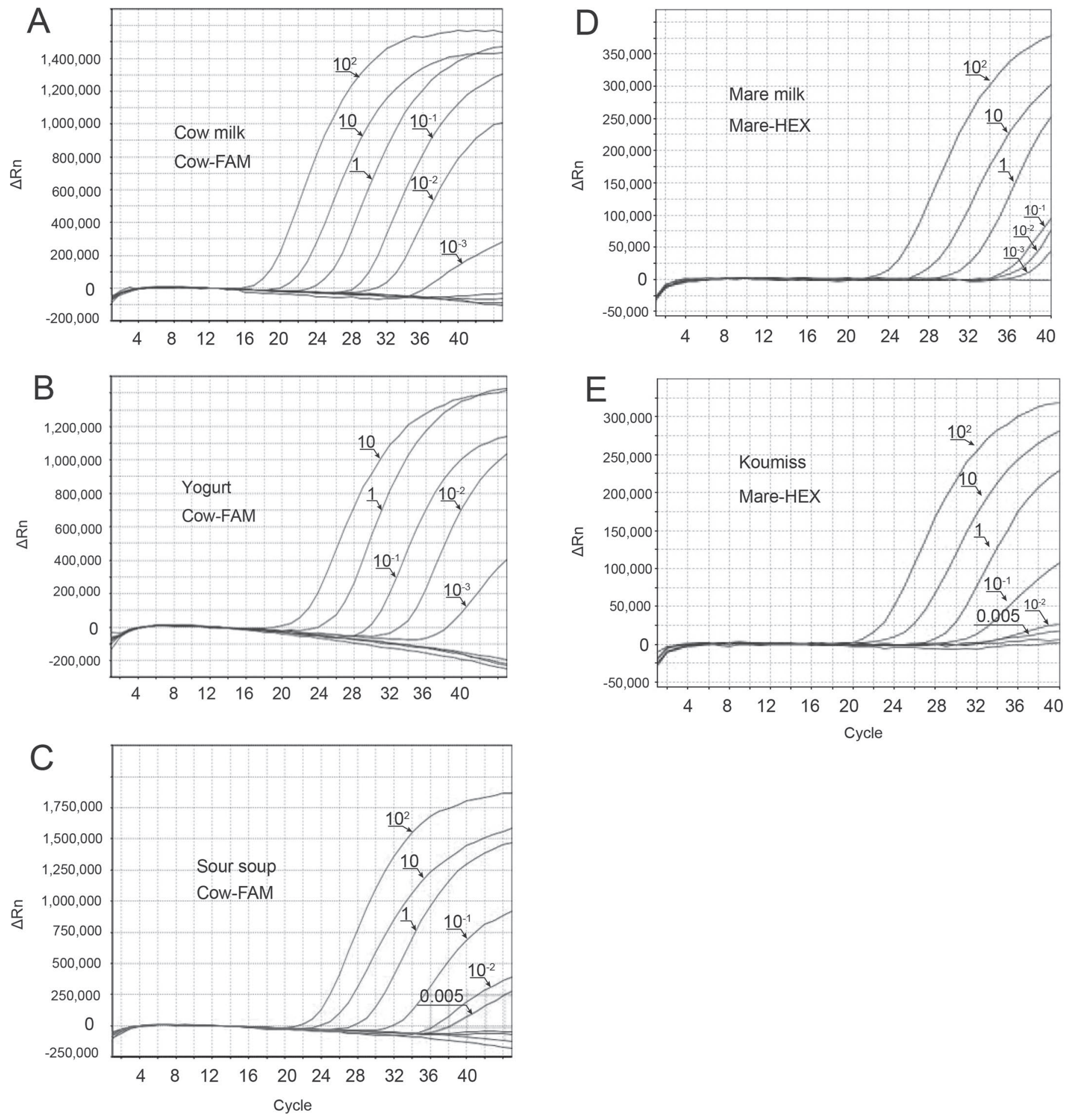

Figure 3. Triplex real-time PCR amplification plots for gradient dilution of DNA extracted from milks and dairy products. Cow milk (A), yogurt (B), sour soup (C), mare milk (D), and koumiss (E) were amplified by the triplex real-time PCR with developed primers and probes. $\mathrm{FAM}=$ fluorescent reporters 6 -carboxyfluorescein; HEX $=$ hexachlorofluorescein; ROX $=$ carboxy-X-rhodamine; $\Delta \mathrm{Rn}=$ change in normalized reported value. 
endogenous control was stably specific for bovine and equine DNA detection in milks and dairy products.

At present, the detection of animal-derived product was largely based on normal PCR (Golinelli et al., 2014) and real-time PCR using fluorescence dye (Agrimonti et al., 2015). Nevertheless, these methodologies were less specific than TaqMan-based real-time PCR. More importantly, it was possible to achieve multiplex real-time PCR to detect many species in one reaction by means of various TaqMan probes. To fulfill the multiplex detection, the obstacle was to develop different primers and probes to simultaneously perform well in one reaction of real-time PCR. No previous research had shown that the triplex real-time PCR with endogenous control was developed for the detection of adulteration in milks and dairy products (López-Calleja et al., 2007a,b; Cottenet et al., 2011; Dalmasso et al., 2011). Specificity assay results in the triplex real-time PCR showed that the primers and probes could cooperate in one reaction for the identification of bovine and equine DNA in milks and dairy products. Simultaneous detection of bovine and equine DNA in one PCR tube contributed to lower the cost of reagents, consumables, and time in half by adding one species probe. The same calculation can be used in the employment of simultaneous endogenous control detection. Furthermore, the endogenous control in the same reaction with animal-derived detection can authentically illustrate the performance of the PCR reaction and truly eliminate false-negative results.

\section{Sensitivity in the Triplex Real-Time PCR Amplification for Milks and Dairy Products}

The LOD of the triplex real-time PCR assay were determined using serially diluted DNA $(100,10,1,0.1$, $0.01,0.005,0.0025,0.001,0.0005,0.00025,0.0001$, and $0.00001 \mathrm{ng})$ extracted from milks and dairy products. The LOD were estimated by Probit analysis using 20 replicates for each dilution. As shown in Figure 3 and Table 4, the LOD of bovine identification in cow milk, yogurt, and sour soup were 0.001, 0.001, and 0.005 ng, respectively (confidence limit: 95\%). The LOD of equine identification in mare milk and koumiss were 0.001 and $0.005 \mathrm{ng}$, respectively (confidence limit: 95\%). The Ct values of the triplex real-time PCR assay using cow milk, yogurt, sour soup, mare milk, and koumiss samples are shown in Table 4 . The Ct values, which were determined by 20 replicates, corresponded to the above amplification plots. Thus, the LOD results illustrated that the triplex real-time PCR assay-based designed primers and probes were sensitive to identify the target DNA.

To develop triplex real-time PCR for animal-derived product detection in milk and dairy products, the sen- sitivity of the assay was performed with the conservative primers and 3 specific probes. The common assay introduced simplex real-time PCR with species-specific primers and probes (Tanabe et al., 2007; Soares et al., 2010; Kim et al., 2016). The LOD representing the sensitivity of the triplex real-time PCR was $1 \mathrm{pg}$ for cow milk (Figure 3A), $1 \mathrm{pg}$ for yogurt (Figure 3B), $5 \mathrm{pg}$ for sour soup (Figure 3C), 1 pg for mare milk (Figure 3D),

Table 4. The cycle threshold $(\mathrm{Ct})$ values in the triplex real-time PCR assay for dilution of DNA

\begin{tabular}{|c|c|c|c|}
\hline \multirow[b]{2}{*}{ Sample } & \multirow{2}{*}{$\begin{array}{l}\text { Input DNA } \\
\text { amount (ng) }\end{array}$} & \multicolumn{2}{|c|}{ Ct value ${ }^{1}$} \\
\hline & & Cow-FAM & Mare-HEX \\
\hline \multirow[t]{10}{*}{ Cow milk } & 100 & $16.24 \pm 0.54$ & 0 \\
\hline & 10 & $19.99 \pm 0.68$ & 0 \\
\hline & 1 & $23.90 \pm 0.36$ & 0 \\
\hline & 0.1 & $28.12 \pm 0.91$ & 0 \\
\hline & 0.01 & $32.05 \pm 0.53$ & 0 \\
\hline & 0.001 & $37.67 \pm 0.86$ & 0 \\
\hline & 0.0005 & 0 & 0 \\
\hline & 0.00025 & 0 & 0 \\
\hline & 0.0001 & 0 & 0 \\
\hline & 0.00001 & 0 & 0 \\
\hline \multirow[t]{9}{*}{ Yogurt } & 10 & $20.06 \pm 1.23$ & 0 \\
\hline & 1 & $24.74 \pm 0.49$ & 0 \\
\hline & 0.1 & $29.51 \pm 0.67$ & 0 \\
\hline & 0.01 & $33.50 \pm 0.61$ & 0 \\
\hline & 0.001 & $37.90 \pm 1.19$ & 0 \\
\hline & 0.0005 & 0 & 0 \\
\hline & 0.00025 & 0 & 0 \\
\hline & 0.0001 & 0 & 0 \\
\hline & 0.00001 & 0 & 0 \\
\hline \multirow[t]{10}{*}{ Sour soup } & 100 & $20.53 \pm 1.27$ & 0 \\
\hline & 10 & $24.39 \pm 1.96$ & 0 \\
\hline & 1 & $29.03 \pm 2.22$ & 0 \\
\hline & 0.1 & $33.87 \pm 2.46$ & 0 \\
\hline & 0.01 & $37.19 \pm 1.29$ & 0 \\
\hline & 0.005 & $38.56 \pm 1.33$ & 0 \\
\hline & 0.0025 & 0 & 0 \\
\hline & 0.001 & 0 & 0 \\
\hline & 0.0001 & 0 & 0 \\
\hline & 0.00001 & 0 & 0 \\
\hline \multirow[t]{10}{*}{ Mare milk } & 100 & 0 & $24.47 \pm 1.88$ \\
\hline & 10 & 0 & $27.08 \pm 1.48$ \\
\hline & 1 & 0 & $28.16 \pm 1.65$ \\
\hline & 0.1 & 0 & $31.16 \pm 1.72$ \\
\hline & 0.01 & 0 & $33.51 \pm 0.48$ \\
\hline & 0.001 & 0 & $36.07 \pm 0.81$ \\
\hline & 0.0005 & 0 & 0 \\
\hline & 0.00025 & 0 & 0 \\
\hline & 0.0001 & 0 & 0 \\
\hline & 0.00001 & 0 & 0 \\
\hline \multirow[t]{10}{*}{ Koumiss } & 100 & 0 & $22.26 \pm 2.61$ \\
\hline & 10 & 0 & $24.69 \pm 3.42$ \\
\hline & 1 & 0 & $26.90 \pm 1.16$ \\
\hline & 0.1 & 0 & $28.94 \pm 1.55$ \\
\hline & 0.01 & 0 & $30.80 \pm 1.08$ \\
\hline & 0.005 & 0 & $31.51 \pm 2.07$ \\
\hline & 0.0025 & 0 & 0 \\
\hline & 0.001 & 0 & 0 \\
\hline & 0.0001 & 0 & 0 \\
\hline & 0.00001 & 0 & 0 \\
\hline
\end{tabular}

${ }^{1}$ Data (average $\pm \mathrm{SD}$ ) represent 20 replicates. FAM $=$ fluorescent reporters 6-carboxyfluorescein; HEX = hexachlorofluorescein. 
and $5 \mathrm{pg}$ for koumiss (Figure 3E). The LOD results differed according to different types of sample. The LOD for milks and dairy products were more sensitive than the previous study (Zhang et al., 2007; Di Domenico et al., 2017). However, the sensitivity for sour soup and koumiss were lower than corresponding data for cow milk, yogurt, and mare milk. During the production of sour soup, the milk was fermented and coagulated by heat. The mare milk took a longer time $(3-4 \mathrm{~d})$ to ferment to become koumiss than yogurt, which did not require heat treatment. We assumed that the long-term fermentation and heat-processed procedure destroyed the integrity of DNA, which brought down the sensitivity of the assay. Relatively poor quality of DNA in dairy products made the detection of DNA more difficult in dairy items than in meats (Kesmen et al., 2009; Fang and Zhang, 2016).

As shown in Figure 4, the calibration curves were constructed by plotting the $\mathrm{Ct}$ values versus the logarithm of DNA solution of cow milk, yogurt, sour soup, mare milk, and koumiss. The calibration curve was determined from 10 replicate analyses. The slopes of the calibration curve were -4.215 for cow milk (Figure $4 \mathrm{~A}),-4.444$ for yogurt (Figure 4B), -4.241 for sour soup (Figure 4C), -2.294 for mare milk (Figure 4D), and -2.118 for koumiss (Figure $4 \mathrm{E}$ ), and the correlation coefficients were 0.995 for cow milk (Figure 4A), 0.999 for yogurt (Figure 4B), 0.997 for sour soup (Figure 4C), 0.99 for mare milk (Figure 4D), and 0.998 for koumiss (Figure 4E). The real-time PCR system developed in this study demonstrated good calibration linearity and was thus regarded to be sufficient to quantify bovine and equine DNA in milks and dairy products. Moreover, the challenge of quantification in food products (particularly in milk products) is still far from being solved. The DNA-based methods can only provide approximate values (Mayer et al., 2012).

\section{Triplex Real-Time PCR Assay for Bovine and Equine DNA Mixtures}

To validate the simultaneous triplex real-time PCR amplification for milks and dairy products, the first artificial binary DNA mixtures containing 1, 5, 10, $20,30,40,50,80,90,95$, and $99 \%$ (wt/wt) of cow in mare were blended, the second artificial binary DNA mixtures of fermented dairy product containing 1, 5, $10,20,30,40,50,80,90,95$, and $99 \%$ (wt/wt) of sour soup in koumiss were blended, and then the mixtures were used as a template for the simultaneous triplex

Table 5. The cycle threshold $(\mathrm{Ct})$ values in the triplex real-time PCR for bovine and equine DNA mixtures

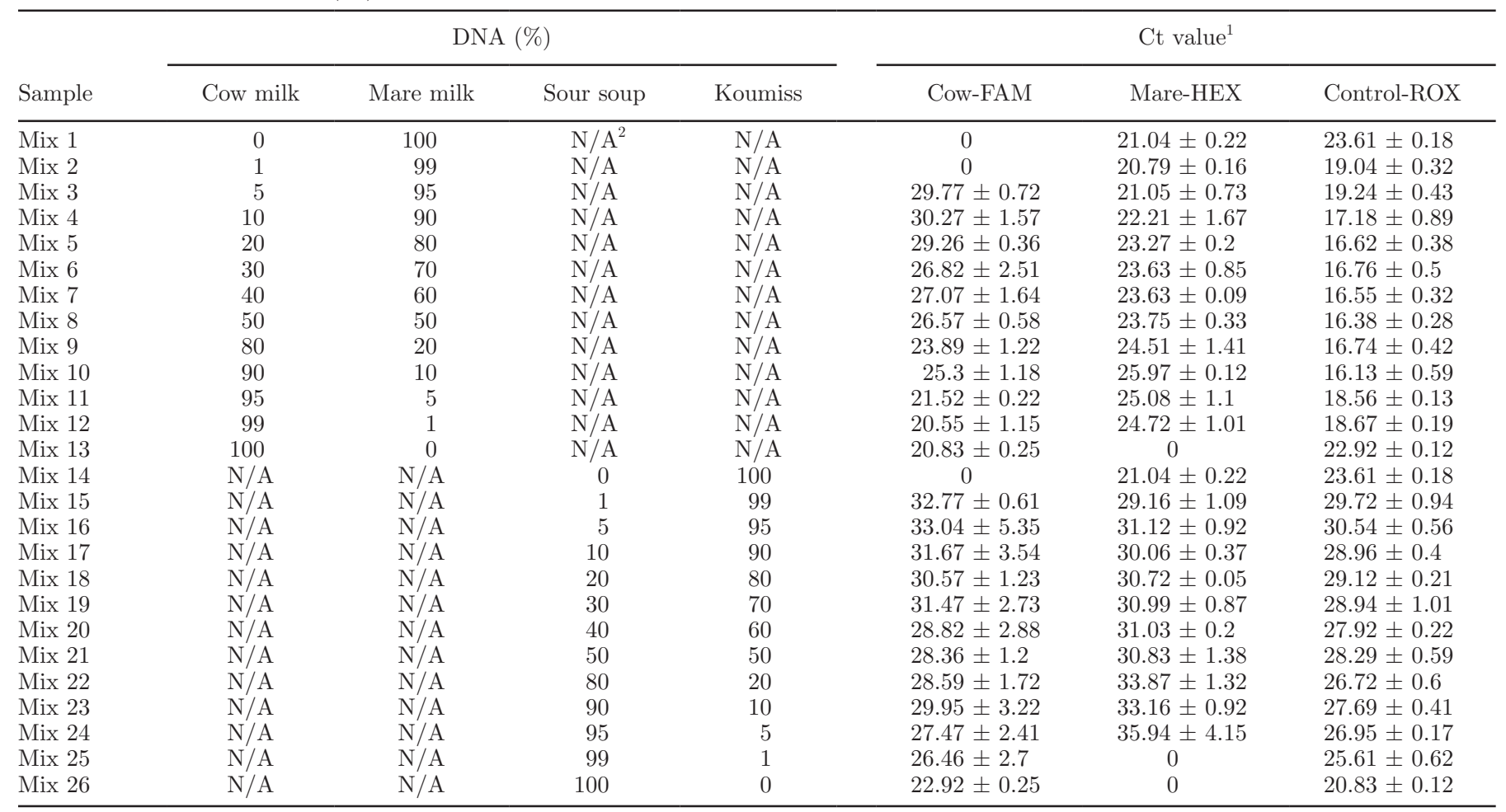

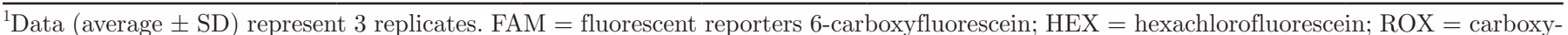
X-rhodamine.

${ }^{2} \mathrm{~N} / \mathrm{A}=$ not applicable. 

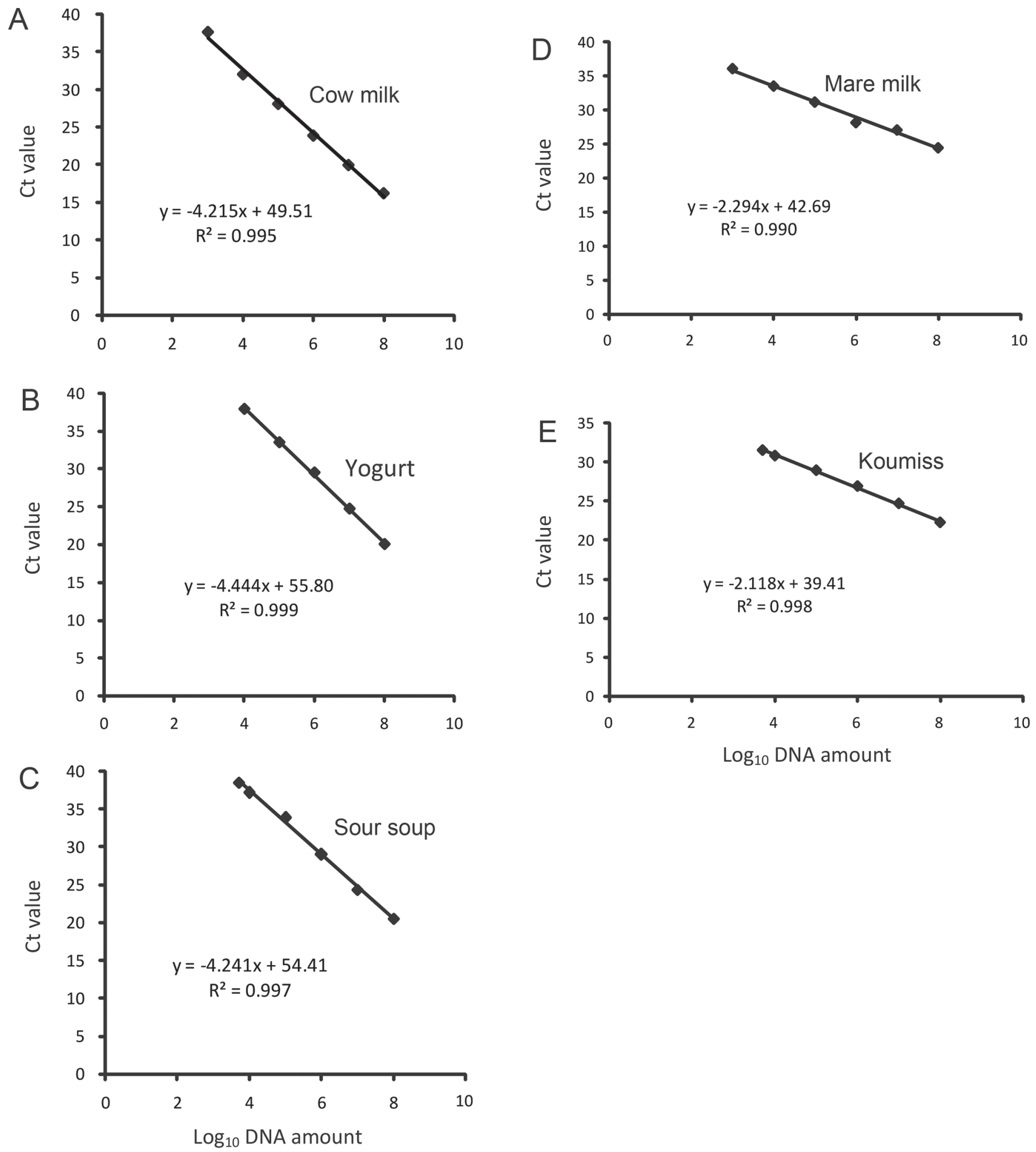

Figure 4. The calibration curves for quantification of the bovine and equine DNA in cow milk (A), yogurt (B), sour soup (C), mare milk (D), and koumiss (E) inferred from triplex real-time PCR. Ct $=$ cycle threshold. 

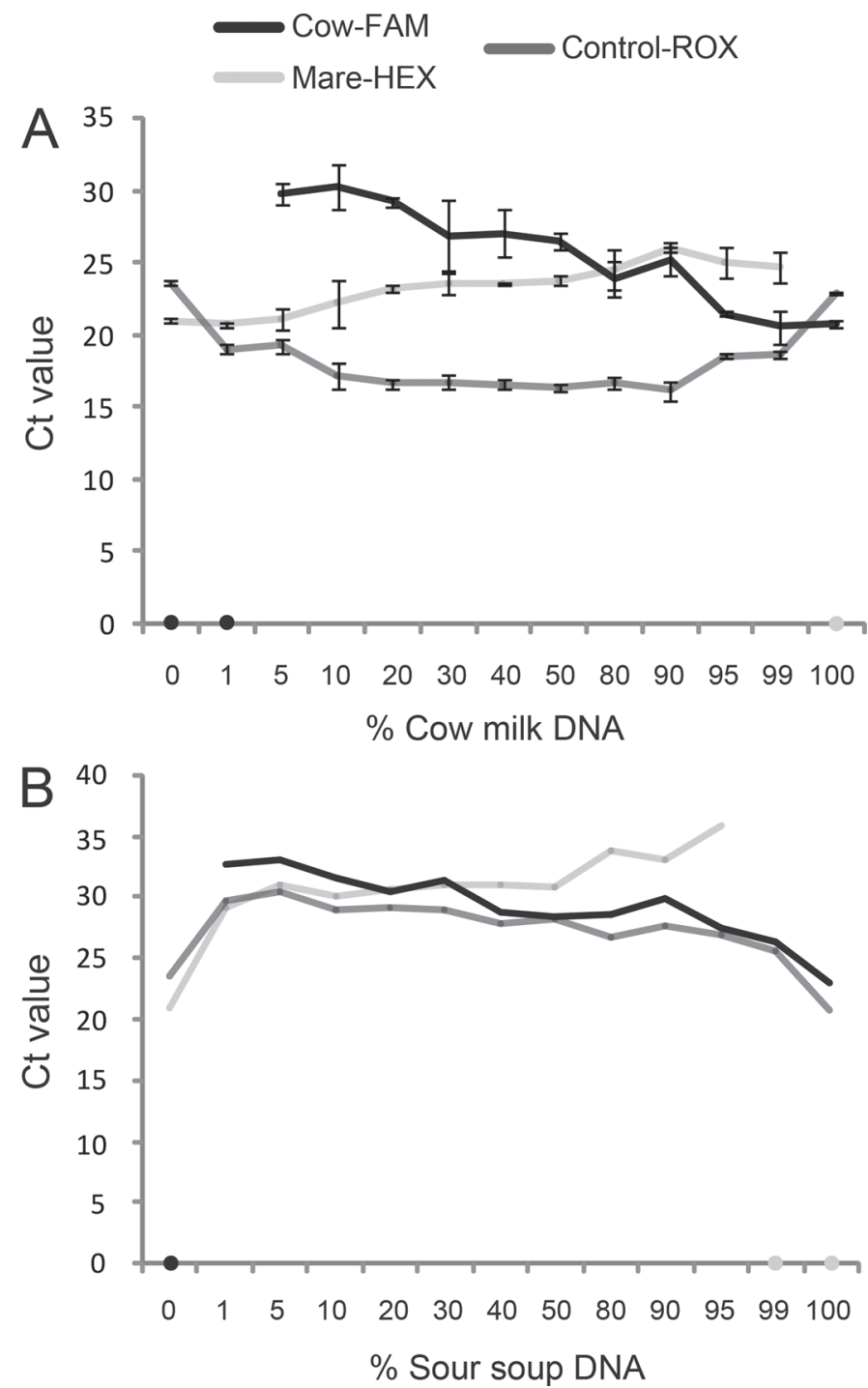

Figure 5. Triplex real-time PCR amplification properties for bovine and equine DNA mixtures. The artificial binary DNA mixtures containing $1,5,10,20,30,40,50,80,90,95$, and $99 \%$ (wt/wt) of cow in mare (A) and sour soup in koumiss (B) were blended for the simultaneous triplex real-time PCR amplification. The results were confirmed by 3 replicates. $\mathrm{Ct}=$ cycle threshold. FAM $=$ fluorescent reporters 6-carboxyfluorescein; HEX = hexachlorofluorescein; ROX = carboxy-X-rhodamine. Error bars represent SD $(\mathrm{n}=3)$.

real-time PCR amplification. As shown in Table 5 and Figure 5A, the cow-specific identification (cow-FAM) in the simultaneous triplex PCR was stably amplified in $\geq 5 \%$ cow in mare DNA template, and failed in $1 \%$. With the increasing cow percentage, the $\mathrm{Ct}$ values were decreased (Figure 5A). As shown in Table 5 and Figure $5 \mathrm{~A}$, the mare-specific identification (mare-HEX) in the simultaneous triplex PCR was stably amplified in $\leq 99 \%$ cow in mare DNA template. With the increasing of cow DNA percentage, the $\mathrm{Ct}$ values were rising
(Figure 5A). The endogenous control was stably amplified in all of the samples (Figure 5A). As shown in Table 5 and Figure 5B, the cow-specific identification (cow-FAM) in the simultaneous triplex PCR was stably amplified in $\geq 1 \%$ sour soup in koumiss DNA. With the increasing cow DNA percentage, the $\mathrm{Ct}$ values were decreasing (Figure 5B). As shown in Table 5 Figure 5B, the mare-specific identification (mare-HEX) in the simultaneous triplex PCR was stably amplified in $\leq 95 \%$ sour soup in koumiss DNA, and failed in 99\%. With the increasing of cow DNA percentage, the $\mathrm{Ct}$ values were rising (Figure 5B). The above data illustrated that the triplex real-time PCR with endogenous control was able to simultaneously detect bovine and equine DNA in the mixtures of DNA from milks and dairy products.

\section{Validation of the Triplex Real-Time PCR for Identification of Mare Milk Adulteration with Cow Milk}

To validate the simultaneous triplex real-time PCR assay for authentication of milk, detection of mare milk adulteration with cow milk was performed by using cow-FAM, mare-HEX, and control-ROX in triplex realtime PCR. First, to simulate the milk adulteration, the artificial binary milk mixtures were blended, and then the DNA that was extracted from the binary mixtures was used as template for the real-time PCR. The percentages of mare milk in the mixtures were $1,5,10,30$, 70, 90, 95, and 99\% (wt/wt), and the corresponding percentages of cow milk in the mixtures were 99, 95, 90, 70, 30, 10, 5, and 1\% (wt/wt; Figure 6, bottom bar). As shown in Figure 6 and Table 6, with the increasing

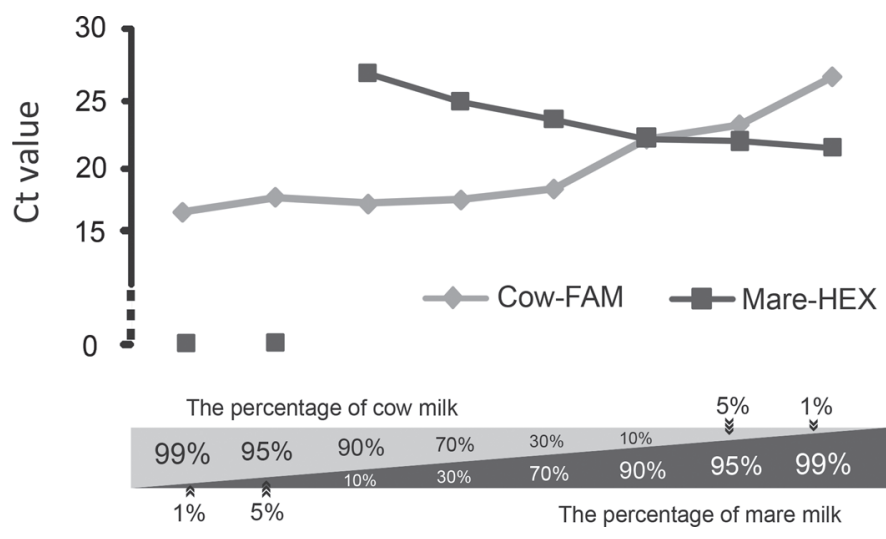

Figure 6. Triplex real-time PCR assay for the identification of cow and mare in the milk mixtures. The artificial binary cow and mare milk mixtures containing 1, 5, 10, 30, 70, 90, 95, and 99\% (wt/wt) of mare in cow and were blended for the simultaneous triplex real-time PCR amplification. The results were confirmed by 20 replicates. Ct = cycle threshold; FAM $=$ fluorescent reporters 6 -carboxyfluorescein; HEX $=$ hexachlorofluorescein. 
Table 6. The cycle threshold $(\mathrm{Ct})$ values in the triplex real-time PCR for cow and mare milk mixtures

\begin{tabular}{lccccc}
\hline & \multicolumn{2}{c}{ Volume (\%) } & & \multicolumn{2}{c}{ Ct value $^{1}$} \\
\cline { 2 - 3 } \cline { 5 - 5 } Sample & Cow milk & Mare milk & & Cow-FAM & Mare-HEX \\
\hline Mix 1 & 99 & 1 & & $16.60 \pm 1.05$ & 0 \\
Mix 2 & 95 & 5 & & $17.68 \pm 1.28$ & 0 \\
Mix 3 & 90 & 10 & & $17.24 \pm 0.86$ & $26.76 \pm 1.55$ \\
Mix 4 & 70 & 70 & & $17.47 \pm 2.50$ & $24.69 \pm 0.81$ \\
Mix 5 & 30 & 90 & & $21.90 \pm 0.95$ & $23.38 \pm 0.81$ \\
Mix 6 & 10 & 95 & & $23.98 \pm 0.72$ & $22.04 \pm 1.61$ \\
Mix 7 & 5 & 99 & & $26.45 \pm 0.95$ & $21.80 \pm 1.82$ \\
Mix 8 & 1 & & & & \\
\hline
\end{tabular}

${ }^{1}$ Data (average $\pm \mathrm{SD}$ ) represent 20 replicates. FAM $=$ fluorescent reporters 6 -carboxyfluorescein; HEX = hexachlorofluorescein.

mare milk in the mixtures, the $\mathrm{Ct}$ values of mare-HEX were decreasing, and the $\mathrm{Ct}$ values for $1 \%$ and $5 \%$ mare percentage were 0 . The sensitivity of identification of mare milk was 10\% (confidence limit: 95\%), and the amplification plots of mare-HEX steadily appeared in $\geq 10 \%$ mare percentages. As shown in Figure 6 and Table 6 , with the decreasing of cow milk in the mixtures, the $\mathrm{Ct}$ values of cow-FAM were increasing and the sensitivity of identification of cow milk was 1\% (confidence limit: 95\%). The amplification plots of cow-FAM steadily appeared in $\geq 1 \%$ cow percentages. More importantly, the endogenous control (controlROX) was steadily amplified in the all 8 mixtures. In short, the simultaneous triplex real-time PCR assay for authentication of milk was validated in the milk mixtures of mare and cow. The above results showed that the triplex real-time PCR with endogenous control was effective to simultaneously and sensitively detect cow and mare origins in milks.

\section{CONCLUSIONS}

The objective of this study was to develop and validate a novel triplex TaqMan real-time PCR technique that was introduced to detect the fraudulent presence of cow milk in mare milk to investigate the prevalence of adulteration. The simultaneous triplex real-time PCR were verified to detect cow and mare DNA in milks with an endogenous control, which was simultaneously used to get rid of possible false negatives. This method was based on the design of the species-conservative primers and species-specific probes. With this assay for the detection of animal-derived products, cow and mare DNA were specifically identified by employing developed primers and probes, and LOD of this assay were 1 pg of cow DNA and $1 \mathrm{pg}$ of mare DNA, respectively. In conclusion, the triplex PCR assay for the multi-channel identification of species origins of meats and milks was verified to be a specific, sensitive, and effective tech- nique for authenticating cattle and horse in meats, and distinguishing cow milk from mare in the market.

\section{ACKNOWLEDGMENTS}

We thank Jian-Jun Zhu and Yong-Ping Yan (Xilingol Vocational College, Xilinhot, China) for providing milks and dairy products. We thank Jian-Ping Sun, Wei-Liang Xu, and Chun-Dong Li (Xilingol Vocational College, Xilinhot, China) for the sampling of experimental materials. This work was supported by the Xilingol Vocational College Key Research Project (ZD2017-10) and the Xilin Gol Institute of Bioengineering Key Research Project (2006001 and 2006002).

\section{REFERENCES}

Agrimonti, C., A. Pirondini, M. Marmiroli, and N. Marmiroli. 2015. A quadruplex PCR (qxPCR) assay for adulteration in dairy products. Food Chem. 187:58-64.

Anguita, G., R. Martin, T. Garcia, P. Morales, A. I. Haza, I. Gonzalez, B. Sanz, and P. E. Hernandez. 1997. A competitive enzyme-linked immunosorbent assay for detection of bovine milk in ovine and caprine milk and cheese using a monoclonal antibody against bovine beta-casein. J. Food Prot. 60:64-66.

Ballin, N. Z. 2010. Authentication of meat and meat products. Meat Sci. $86: 577-587$.

Cottenet, G., C. Blancpain, and P. A. Golay. 2011. Simultaneous detection of cow and buffalo species in milk from China, India, and Pakistan using multiplex real-time PCR. J. Dairy Sci. 94:37873793.

Cozzolino, R., S. Passalacqua, S. Salemi, and D. Garozzo. 2002. Identification of adulteration in water buffalo mozzarella and in ewe cheese by using whey proteins as biomarkers and matrix-assisted laser desorption/ionization mass spectrometry. J. Mass Spectrom. 37:985-991.

Dalmasso, A., T. Civera, F. L. Neve, and M. T. Bottero. 2011. Simultaneous detection of cow and buffalo milk in mozzarella cheese by Real-Time PCR assay. Food Chem. 124:362-366.

Di Domenico, M., M. Di Giuseppe, J. D. Wicochea Rodriguez, and C. Camma. 2017. Validation of a fast real-time PCR method to detect fraud and mislabeling in milk and dairy products. J. Dairy Sci. 100:106-112.

Fang, X., and C. Zhang. 2016. Detection of adulterated murine components in meat products by TaqMan real-time PCR. Food Chem. 192:485-490. 
Ferreira, I. M., and H. Cacote. 2003. Detection and quantification of bovine, ovine and caprine milk percentages in protected denomination of origin cheeses by reversed-phase high-performance liquid chromatography of beta-lactoglobulins. J. Chromatogr. A 1015:111-118.

Finney, D. J. 1971. Probit Analysis. 3rd ed. Cambridge University Press, Cambridge, UK.

Golinelli, L. P., A. C. Carvalho, R. S. Casaes, C. S. Lopes, R. Deliza V. M. Paschoalin, and J. T. Silva. 2014. Sensory analysis and species-specific PCR detect bovine milk adulteration of frescal (fresh) goat cheese. J. Dairy Sci. 97:6693-6699.

Kesmen, Z., A. Gulluce, F. Sahin, and H. Yetim. 2009. Identification of meat species by TaqMan-based real-time PCR assay. Meat Sci. 82:444-449.

Kim, M., I. Yoo, S. Y. Lee, Y. Hong, and H. Y. Kim. 2016. Quantitative detection of pork in commercial meat products by $\operatorname{TaqMan}(\mathrm{R})$ real-time PCR assay targeting the mitochondrial D-loop region. Food Chem. 210:102-106.

López-Calleja, I., I. González, V. Fajardo, I. Martín, P. E. Hernández, T. García, and R. Martín. 2007a. Quantitative detection of goats milk in sheep's milk by real-time PCR. Food Control 18:1466-1473.

López-Calleja, I., I. González, V. Fajardo, I. Martín, P. E. Hernández T. García, and R. Martín. 2007b. Real-time TaqMan PCR for quantitative detection of cows' milk in ewes' milk mixtures. Int. Dairy J. 17:729-736.

Mane, B. G., S. K. Mendiratta, and A. K. Tiwari. 2012. Beef specific polymerase chain reaction assay for authentication of meat and meat products. Food Control 28:246-249.

Mayer, H. K., J. Bürger, and N. Kaar. 2012. Quantification of cow's milk percentage in dairy products-A myth? Anal. Bioanal. Chem. 403:3031-3040.
Murray, M. G., and W. F. Thompson. 1980. Rapid isolation of high molecular weight plant DNA. Nucleic Acids Res. 8:4321-4325.

Nakyinsige, K., Y. B. Man, and A. Q. Sazili. 2012. Halal authenticity issues in meat and meat products. Meat Sci. 91:207-214.

Park, Y. W. 2009. Bioactive Components in Milk and Dairy Products. Wiley-Blackwell, Ames, IA.

Rahmati, S., N. M. Julkapli, W. A. Yehye, and W. J. Basirun. 2016. Identification of meat origin in food products-A review. Food Control 68:379-390.

Rong, J., H. Zheng, M. Liu, X. Hu, T. Wang, X. Zhang, F. Jin, and L. Wang. 2015. Probiotic and anti-inflammatory attributes of an isolate Lactobacillus helveticus NS8 from Mongolian fermented koumiss. BMC Microbiol. 15:196.

Soares, S., J. S. Amaral, I. Mafra, and M. B. Oliveira. 2010. Quantitative detection of poultry meat adulteration with pork by a duplex PCR assay. Meat Sci. 85:531-536.

Tanabe, S., M. Hase, T. Yano, M. Sato, T. Fujimura, and H. Akiyama. 2007. A real-time quantitative PCR detection method for pork, chicken, beef, mutton, and horseflesh in foods. Biosci. Biotechnol. Biochem. 71:3131-3135.

Yao, G., J. Yu, Q. Hou, W. Hui, W. Liu, L. Y. Kwok, B. Menghe, T. Sun, H. Zhang, and W. Zhang. 2017. A perspective study of koumiss microbiome by metagenomics analysis based on single-cell amplification technique. Front. Microbiol. 8:165.

Zhang, C.-L., M. R. Fowler, N. W. Scott, G. Lawson, and A. Slater 2007. A TaqMan real-time PCR system for the identification and quantification of bovine DNA in meats, milks and cheeses. Food Control 18:1149-1158. 